\title{
COMPOSIÇÃO QUÍMICA E SUSCEPTIBILIDADE DO ÓLEO ESSENCIAL DE ÓREGANO (ORIGANUM VULGARE L., FAMÍLIA LAMIACEAE) FRENTE À CEPAS DE ESCHERICHIA COLI, STAPHYLOCOCCUS AUREUS E SALMONELLA CHOLERAESUIS
}

\author{
Luana Silva Araújo*1 \\ Renato Silva Araújo*1 \\ Josilene Lima Serra**2 \\ Adenilde Ribeiro Nascimento ${ }^{* * * 3}$
}

\begin{abstract}
O orégano (Origanum vulgare L., família Lamiaceae) é uma planta condimentar que além de apresentar propriedades aromáticas apresenta também propriedades antimicrobianas e antioxidantes, que atuam como conservantes naturais inibindo o crescimento de micro-organismos. Este estudo teve como objetivo determinar a composição química e avaliar a atividade antibacteriana do óleo essencial de orégano frente às cepas de Escherichia coli, Staphylococcus aureus e Salmonella choleraesuis. O método empregado para extração do óleo essencial de orégano foi de arraste de vapor d'água, utilizado o extrator de Clevenger. Para a identificação dos constituintes utilizou-se a técnica de Cromatografia a gás acoplada à espectrometria de massas, encontrando-se 25 constituintes, sendo o 4-terpineol e timol os compostos majoritários, seguido pelo $\alpha$-terpineno, $p$-cimeno, allocimeno, $\beta$-terpineol $e$ acetato de linalina. A atividade antimicrobiana do óleo e a avaliação da susceptibilidade das cepas testes aos antibióticos comerciais foram avaliadas através do método de difusão de discos. O óleo essencial de orégano apresentou uma excelente atividade antibacteriana, obtendo-se halos de inibição de $13,5 \mathrm{~mm}, 27,5 \mathrm{~mm}$ e 12,5mm sobre E.coli (ATCC 25922), S. aureus (ATTCC 25923) e S. choleraesuis (ATTCC 12011). Todos os patógenos testados apresentaram sensibilidade ao óleo essencial de orégano, sendo observado maior ação do óleo sobre a bactéria Gram-positiva. Com base nos resultados obtidos conclui-se que o óleo essencial de orégano apresentou uma excelente ação antibacteriana, podendo ser utilizado como um conservante natural de alimentos.
\end{abstract}




\section{INTRODUÇÃO}

As mudanças nos hábitos alimentares dos consumidores têm aumentado a sua preocupação com a qualidade e segurança dos alimentos, principalmente, devido aos índices alarmantes de Doenças Transmitidas por Alimentos (DTA's) ocorridos no Brasil nos últimos onze anos (MINISTÉRIO DA SAÚDE, 2011).

Em decorrência disso, a busca por compostos antimicrobianos naturais tem se intensificado com o propósito de serem aplicados na conservação de alimentos (BURT, 2004). Os óleos essenciais extraídos de plantas condimentares têm sido considerados uma fonte segura de antimicrobianos naturais, por não apresentarem riscos a saúde dos consumidores. Diversos estudos tem reportado o efeito inibitório dos óleos essenciais sobre diferentes micro-organismos contaminantes de alimentos (TRAJANO et al., 2009; SANTOS et al., 2011).

Os óleos essenciais (OE) são líquidos aromáticos oleosos obtidos a partir do material vegetal (flores, brotos, sementes, folhas, galhos, cascas, ervas, madeira, frutos e raízes). Estes podem ser obtidos pela fermentação ou extração, mas o método de arraste a vapor é o mais comumente usados para fins comerciais. Estima-se o reconhecimento de mais de 3.000 tipos de óleos essenciais, dos quais 300 possuem aplicações comerciais (PEREIRA, 2011).

$\mathrm{Na}$ natureza, os óleos essenciais desempenham um papel importante na proteção das plantas como agentes antibacterianos, antivirais, antifúngicos, inseticidas e também contra herbívoros. Eles também servem para atrair alguns insetos que favorecem a dispersão de pólen e sementes, ou mesmo para repelir outros insetos indesejáveis. Os óleos essenciais são extraídos de diversas plantas aromáticas geralmente localizadas em países de clima temperado e/ou quente como Mediterrâneo e países tropicais (BARBOSA, 2010).

Os óleos essenciais de plantas condimentares são bastante conhecidos por suas propriedades antimicrobianas e antioxidades. O orégano é uma planta condimentar frequentemente utilizada na culinária com a finalidade principal de conferir sabor e aroma aos alimentos. $\mathrm{O}$ óleo essencial extraído das folhas do orégano tem sido reportado por suas propriedades antimicrobianas sobre fungos, bactérias Gram-positivas e Gram-negativas. Pesquisas comprovam os efeitos antimicrobianos do óleo essencial de orégano sobre diversos patógenos, como espécies dos gêneros Escherichia, Salmonella, Staphylococcus, Aspergillus, Fusarium, Penicillium e Rhizoctonia. Contudo, essa atividade bactericida pode variar de acordo com os teores dos componentes químicos presentes nesse óleo, principalmente o timol e carvacrol (MILOS et al., 2000; PEREIRA, 2006; SILVA et al., 2010; SANTOS et al., 2011).

Dessa forma, o objetivo deste estudo foi determinar a composição química e avaliar a susceptibilidade do óleo essencial de orégano frente as cepas de Escherichia coli, Staphylococcus aureus e Salmonella choleraesuis.

\section{MATERIAL E MÉTODOS}

\subsection{EXTRAÇÃO DO ÓLEO ESSENCIAL}

As folhas de orégano secas foram adquiridas no comércio informal da cidade de São LuísMA. A extração do óleo essencial das folhas de orégano foi realizado no Laboratório de FísicoQuímica do Programa de Controle de Qualidade de Alimentos e Água da Universidade Federal do Maranhão. Inicialmente, 300 gramas de folhas secas de orégano maceradas foram transferidas para um balão de fundo chato de 6 litros, sendo em seguida adicionado água destilada na proporção de 1:10 (massa:volume). O método empregado foi o de hidrodestilação, utilizando o extrator de Clevenger. Após o processo de extração, o óleo coletado foi seco por meio de percolação com $\mathrm{Na}_{2} \mathrm{SO}_{4}$ anidro e armazenado em recipiente adequado.

\subsection{ANÁLISE CROMATOGRÁFICA}

As análises cromatográficas foram realizadas no Laboratórios de Produtos Naturais da Universidade Estadual de Campinas, para a identificação dos constituintes do óleo essencial de 
orégano, utilizou-se a técnica de Cromatografia a Gás acoplada à Espectrometria de Massas (CG/

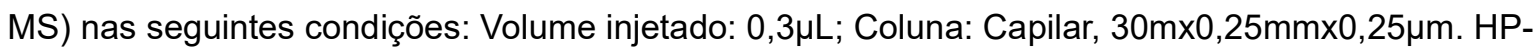
5MS, $5 \%$ difenil, 95\% dimetil polisiloxano (Equivalente DB-\%MS ou CP-Sil 8CB LBIMS); Gás de arraste: $\mathrm{He}(99,9995 \%)$; fluxo: $1,0 \mathrm{~mL}$ min-1; Injetor: $280^{\circ} \mathrm{C}$, modo Split (1:10); Forno: $40^{\circ} \mathrm{C}$ (5,0min) $\rightarrow 240^{\circ} \mathrm{C}\left(4^{\circ} \mathrm{C}\right.$ min-1); $240^{\circ} \mathrm{C} \rightarrow 300^{\circ} \mathrm{C}\left(8^{\circ} \mathrm{C}\right.$ min-1, 7,5min); tT=60,0min; Detector: EM; El (70 eV);. Para a identificação dos compostos detectados nas amostras, utilizaram-se as bases de dados de espectros de massas NIST105, NIST21 e WILEY139.

\subsection{TESTES DE SUSCEPTIBILIDADE}

A atividade antimicrobiana do óleo essencial foi avaliada através do método de difusão de disco (BAUER et al, 1966), conforme descrito posteriormente.

\subsubsection{PREPARO DO INÓCULO}

Cepas testes de Escherichia coli (ATCC 25922), Staphylococcus aureus (ATTCC 25923) e Salmonella choleraesuis (ATTCC 12011) foram ativadas em caldo Brain Heart Infusion (BHI) e após 24 horas de incubação foi realizado a padronização do inoculo com a escala 0,5 de Mac Farland $\left(10^{-8}\right.$ micro-organismos/ $\left.\mathrm{mL}\right)$.

\subsubsection{MÉtodo de Difusão de Discos (MDD)}

Com auxílio de um swab, o inóculo $(0,1 \mathrm{~mL})$ de cada bactéria teste, foi semeada sobre a superfície das placas de ágar Mueller-Hinton. Em seguida, sobre este, foram aderidos pequenos discos de papel de filtro impregnados com $75 \mu \mathrm{L}$ do óleo essencial de orégano, com o auxílio de uma pinça previamente flambada. Os discos foram pressionados levemente contra a superfície do meio. As placas foram incubadas a $35^{\circ} \mathrm{C}$ por 24 horas e posteriormente foi realizada a leitura do halo de inibição com uma régua milimetrada. Para controle positivo, foi realizada a avaliação de susceptibilidade das cepas testes a antibióticos comerciais (penicilina $10 \mu \mathrm{g}$ e vancomicina $30 \mu \mathrm{g}$ ) pelo método de difusão de discos supracitado.

\section{RESULTADOS E DISCUSSÕES}

A Figura 1 apresenta o cromatograma do óleo essencial de orégano obtido pelo sistema de hidrodestilação de Clevenger. A análise cromatográfica identificou 25 constituintes, tendo o 4-terpineol e timol como compostos majoritários, seguido pelo a-terpineno, p-cimeno, allocimeno, $\beta$-terpineol e acetato de linalina.

Resultados similares foram observados por Cleff et al. (2010), sendo o 4-terpineol e timol os compostos encontrados em maiores concentrações. Os autores também destacam que fenóis, como carvacrol, timol, gamaterpeno e p-cimeno são os compostos ativos do óleo essencial do orégano, representando 70 a $98 \%$ da sua composição.

Milos et al. (2000) identificaram um total de 16 compostos no óleo essencial do orégano, entre eles estão o timol, carvacrol, p-cimeno e g-terpeno. O conteúdo de compostos fenólicos do óleo essencial de orégano, depende de fatores abióticos, tais como, a localização geográfica da planta, condições ambientais, época de colheita entre outros e do método de extração (MARINO et al., 2001). De fato, Silva et al. (2010) observaram uma grande variação nos teores de timol e carvacrol no óleo essencial de orégano proveniente de cinco marcas comerciais diferentes.

A Tabela 1 apresenta dados referentes à ação antibacteriana do óleo essencial de orégano avaliada pelo método de difusão de discos. O óleo essencial de orégano apresentou maior atividade antibacteriana sobre o Staphylococcus aureus apresentando halo de inibição de $27,5 \mathrm{~mm}$, enquanto que os menores halos de inibição foram obtidos para a Salmonella choleraesuis e Escherichia coli. 


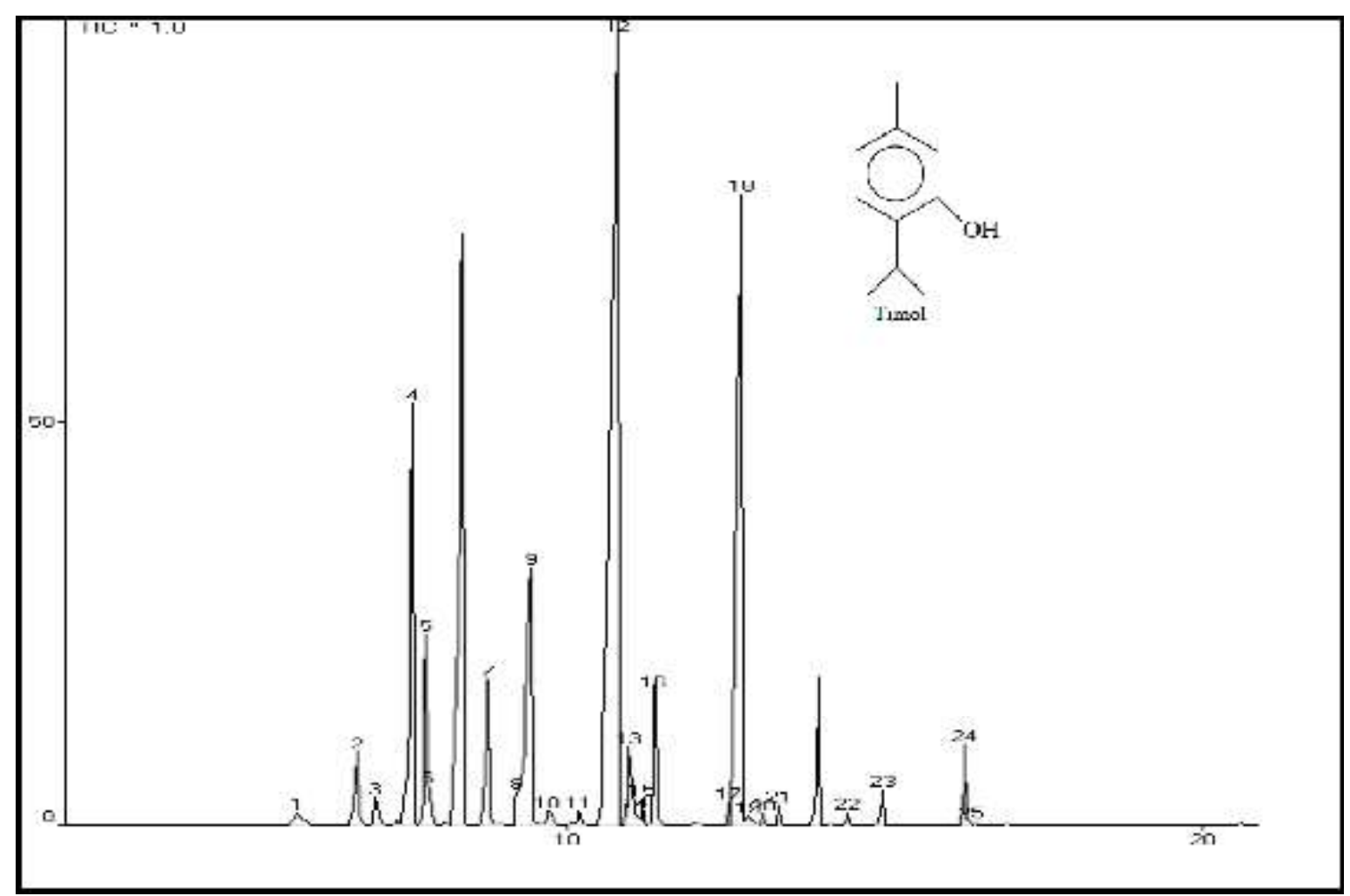

FIGURA 1. CROMATOGRAMA DO ÓLEO ESSENCIAL DO ORÉGANO, APRESENTANDO OS PRINCIPAIS CONSTITUINTES IDENTIFICADOS, P=PICO: A-TERPINENO (P4), P-CIMENO (P5), ALLOCIMENO (P7), B-TERPINEOL (P9), 4-TERPINEOL (P12), ACETATO DE LINOLINA (P16), TIMOL (P18). *COMPOSTOS IDENTIFICADOS POR COMPARAÇÃO COM O TEMPO DE RETENÇÃO DOS PADRÕES.

TABELA 1. HALOS DE INIBIÇÃO DO ÓLEO ESSENCIAL DE ORÉGANO FRENTE E ANTIBIÓTICOS COMERCIAIS FRENTE AS CEPAS DE Escherichia coli (ATCC 25922),

STaphylococcus aureus (ATTCC 25923) E Salmonella choleraesuis (ATTCC 12011).

\begin{tabular}{c|c|c|c}
\hline \multirow{2}{*}{ Óleo essencial } & \multicolumn{3}{|c}{ Halos de inibição (mm)* } \\
\cline { 2 - 4 } & Escherichia coli & Staphylococcus aureus & $\begin{array}{c}\text { Salmonella } \\
\text { choleraesuis }\end{array}$ \\
\hline Origanum vulgare L. & 13,5 & 27,7 & 12,5 \\
\hline
\end{tabular}

Nota: *Médias obtidas das análises realizadas em duplicatas.

Moreira et al (2005) classificam a sensibilidade dos micro-organismos frente à ação dos óleos essenciais de acordo com o tamanho do diâmetro do halo de inibição formado, sendo considerados resistentes $(R)$ halos de inibição com diâmetro inferior a $8 \mathrm{~mm}$ e sensível (S), diâmetros de 9-14 mm. Com base nesses dados, todas as bactérias testadas podem ser considerados sensíveis a ação do óleos essencial de orégano.

A atividade antibacteriana do óleo essencial de orégano frente às espécies Staphylococcus aureus., Escherichia coli e Salmonella sp. tem sido comprovado por outros pesquisadores, os quais relatam baixas concentrações inibitórias para esses micro-organismos, estando em torno de 128 , 512 e $529 \mu \mathrm{g} \cdot \mathrm{mL}^{-1}$, respectivamente (POZZO et al., 2011; VERAS, 2011).

A ação antibacteriana dos óleos essenciais está diretamente relacionada com a composição 
química. Segundo Pozzo (2011), a atividade antibacteriana do óleo essencial de orégano deve-se ao conteúdo de carvacrol e timol presentes nesse óleo. De fato, Burt (2004) relata que os princípios ativos, provocam distorção na estrutura física da célula, causando expansão e consequente desestabilidade na membrana celular, modificando sua permeabilidade, desnaturando enzimas essenciais e alterando a força elétron motora, por meio de variações no $\mathrm{pH}$ e potencial elétrico.

O timol e carvacrol apresentam atividades semelhantes frente a diversas bactérias, no entanto já foram constatadas diferenças na ação destes elementos contra espécies de bactérias Gram-positivas e Gram-negativas (ARAUJO, 2010). Durante esse estudo, observou-se uma maior eficiência do óleo essencial de orégano frente a bactéria Gram-positiva do que as bactérias Gramnegativas testadas, o que pode estar relacionado as características lipofílicas da parede celular das bactérias Gram-positivas, facilitando dessa forma a ação do óleo essencial na membrana celular.

Marino et al. (2001) analisando o efeito antimicrobiano de várias especiarias notaram que o óleo essencial de orégano foi o mais efetivo na inibição de bactérias Gram-positivas e Gramnegativas, causando um alongamento da fase lag. Ademais, tal produto, apresentou-se como eficiente substância bactericida, detectado pela não recuperação de tais micro-organismos após reincubação em meio de recuperação. Entre as cepas Gram-negativas, a E.coli O157: $\mathrm{H} 7$ foi a mais sensível, enquanto que a Listeria monocytogenes e espécies da família Bacilaceae foram os mais sensiveis entre os Gram-positivos analisados.

Veras (2011) observou que não houve diferença significativa entre a ação bactericida do óleo essencial do orégano e o timol, indicando que o timol é responsável pela bioatividade desse óleo. Entretanto, os demais componentes podem agir sinergicamente aumentando o potencial antimicrobiano (BURT, 2004), o que infere-se portanto que o efeito inibitório do óleo essencial de orégano analisado pode ser resultante da interação do 4-terpineol e timol, componentes majoritários desse óleo.

\section{CONCLUSÃO}

Com base nos resultados obtidos conclui-se que o óleo essencial de orégano apresentou uma excelente ação antibacteriana sobre as cepas de Escherichia coli (ATCC 25922), Staphylococcus aureus (ATTCC 25923) e Salmonella choleraesuis (ATTCC 12011), tendo como componentes químicos majoritários o 4-terpineol e timol. Dessa forma, o óleo essencial de orégano constitui-se uma fonte alternativa para a conservação de alimentos, principalmente no controle microbiológico, como também pode ser aplicado como aromatizante natural.

\section{ABSTRACT}

\section{CHEMICAL COMPOSITION AND SUSCEPTIBILITY OF OREGANO ESSENTIAL OIL (ORIGANUM VULGARE L., LAMIACEAE) ON STRAINS OF ESCHERICHIA COLI, STAPHYLOCOCCUS AUREUS AND SALMONELLA CHOLERAESUIS}

Oregano (Origanum vulgare L., Lamiaceae) is a spice plant that besides having aromatic properties also has antimicrobial and antioxidants properties, which act as natural preservatives to inhibit the growth of micro -organisms. This study aimed to determine the chemical composition and evaluate the antibacterial activity of the essential oil of oregano against the strains of Escherichia coli, Staphylococcus aureus and Salmonella choleraesuis. The method used for extraction of essential oil of oregano was the drag of water vapor with the extractor Clevenger. For the identification of the constituents used the technique of chromatography coupled with mass spectrometry gas, obtaining 25 constituents with the 4 - terpineol and thymol the major compounds, followed by $\alpha$ - terpinene, 
$p$ - cymene, allocimeno, $\beta$-terpineol and linalina acetate. The antimicrobial activity of the oil and assessment of the susceptibility of the test strains to commercial antibiotics were evaluated using the disc diffusion method. The essential oil of oregano exhibited excellent antibacterial activity, resulting in inhibition zones of $13.5 \mathrm{~mm}, 27.5 \mathrm{~mm}$ and $12.5 \mathrm{~mm}$ for $E$. coli (ATCC 25922), S. aureus (ATTCC 25923) and S. choleraesuis ( ATTCC 12011 ). All pathogens tested were susceptible to essential oil of oregano, being observed the larger action of the oil on the bacteria Gram-positive. Based on the results obtained it is concluded that the essential oil of oregano exhibited excellent antibacterial activity and can be used as a natural food preservative.

KEY-WORDS: OREGANO, BACTERIA AND ANTIMICROBIAL.

\section{REFERÊNCIAS}

1 ARAUJO, R. C. Óleos essenciais de plantas brasileiras como manipuladores da fermentação ruminal in vitro. Tese apresentada à Universidade de São Paulo Escola Superior de Agricultura "Luiz de Queiroz", Piracicaba, 181p, 2010.

2 BARBOSA, L. N. Propriedade antimicrobiana de óleos essenciais de plantas condimentares com potencial de uso como conservante em carne e hambúrguer bovino e testes de aceitação. 121p. Dissertação (Mestrado em Biologia Geral e Aplicada) Universidade Estadual Paulista. Botucatu. São Paulo. 2010.

3 BURT, S. Essential oils: their antibacterial properties and potential applications in foods: a review. International Journal of Food Microbiology, Amsterdam, v. 94, n. 3, p. 223-253, Aug. 2004.

4 CLEFF, M. B.; MEINERZ, A. R.; FARIA, R.O.; XAVIER, M.O.; SANTIN , R.; NASCENTE, P.S.; RODRIGUES, M.R.; MEIRELES, M. C. A. Atividade inibitória do óleo essencial de orégano em fungos de importância médica e veterinária. Arquivo Brasileiro de Medicina Veterinária e Zootecnia, v.62, n.5, p.1291-1294, 2010.

5 MARINO, M.; BERSANI, C.; COMI, G. Impedance measurements to study the antimicrobial activity of essential oils from Lamiaceae and Compositae. International Journal of Food Microbiology. 67: 187-195, 2001.

6 MILOS, M.; MASTELIC, J.; JERCOVIK, L. Chemical composition and oxidant effect of glicosidically bound volatile compounds from orégano (Origanum vulgare L. spp. hirtum). Food Chemistry. v.71, p. 79-83, 2000.

7 MINISTÉRIO DA SAÚDE. Dados Epidemiológicos -DTA período de 2000 a 2011. Disponível: http://portal.saude.gov. br/portal. Acesso em: 02/01/2013. 2011.

8 MOREIRA, M.R.; PONCE, A.G.; DEL VALLE, C.E.. ROURA, S.I. Inhibitory parameters of essential oils to reduce a foodborne pathogen. Food Science and Technology, v. 38, p.565-570, 2005.

9 PEREIRA, A. A. Efeito Inibitório de Óleos Essenciais Sobre o Crescimento de Bactérias e Fungos. 72 p. Tese de conclusão de curso (Mestrado de ciência de alimentos). Universidade de Federal de Lavras. Lavras, Minas Gerais, 2006.

10 POZZO, M. D.; VIÉGAS, J.; SANTURIO, D. F.; ROSSATTO, L.; SOARES, I. H.; ALVES, S. H.; COSTA, M. M. Atividade antimicrobiana de óleos essenciais de condimentos frente a Staphylococcus spp isolados de mastite caprina. Ciência Rural, v.41, n.4, abr, 2011.

11 SANTOS, J. C.; CARVALHO FILHO, C. D.; Barros, T. F.; Guimarães, A. G. Atividade antimicrobiana in vitro dos óleos essenciais de orégano, alho, cravo e limão sobre bactérias patogênicas isoladas de vôngole. Seminário: Ciências Agrárias, Londrina, v. 32, n. 4, p. 1557-1564, out./dez., 2011.

12 SILVA J. P. L., et al., Óleo essencial de orégano: interferência da composição química na atividade frente a Salmonella Enteritidis. Revista de Ciência e Tecnologia de Alimentos, Campinas, v. 30, p.136-141, 2010.

13 TRAJANO, V. N.; SOUZA, E. L.; TRAVASSOS, A. E. R. Propriedade antibacteriana de óleos essenciais de especiarias sobre bactérias contaminantes de alimentos. Ciência e Tecnologia de Alimentos, Campinas, v. 29, n. 3, p. 542-545, jul.-set., 2009.

14 VERAS, H. N. H. Caracterização química e avaliação da atividade antimicrobiana e antiinflamatória tópica do óleo essencial de Lippia sidoides Cham. (Verbenaceae). Dissertação (Mestrado em Bioprospecção Molecular) - Programa de Pós-Graduação em Bioprospecção Molecular da Universidade Regional do Cariri - URCA. Crato, Ceará, 2011. 